\title{
An illusionary prosthetic design for a unilateral cleft palate patient
}

\author{
Andaç Barkın Bavbek, Ahmet Kursad Culhaoglu ${ }^{1}$ \\ Department of Prosthodontics, Faculty of Dentistry, Van Yüzüncüyıl University, Van, ${ }^{1}$ Dr. Mediha \\ Eldem Sokak, 70/11 Kocatepe, Ankara, Turkey
}

\author{
Address for correspondence: \\ Dr. Ahmet Kursad Culhaoglu, \\ Dr. Mediha Eldem Sokak, \\ 70/11 Kocatepe, Ankara, Turkey. \\ E-mail: ahmetculhaoglu@hotmail.com
}

\begin{abstract}
The prosthetic rehabilitation is an important part of the cleft lip and palate therapy assisting orthodontic and orthognathic treatments. Prosthesis does not only help to improve function and aesthetics but also needs to facilitate a better oral health. The aim of this report is to introduce the prosthetic approach of a 21-year-old female unilateral cleft palate patient that considered reinforcing the mobile canine adjacent to the cleft, easing the elimination of dental plaque from the remaining fistula and reaching an accurate occlusion. Facial aesthetics was established by the illusionary effect of a removable crown complex which is joined onto a fixed partial denture with a precision attachment system.
\end{abstract}

Key words

Cleft palate, illusionary effect, precision attachment

\section{INTRODUCTION}

Cleft lip and palate is considered to be one of the most frequent congenital deformities of the orofacial complex. ${ }^{[1]}$ Worldwide, approximately one in every 800 births results in a cleft lip and/or palate. ${ }^{[2,3]}$ Although the aetiology of cleft lip and palate has not yet been totally understood, cleft lip is a result of a deficiency in fusion of the median and lateral nasal processes whereas a failure of fusion of palatal shelves results with cleft palate. ${ }^{[4,5]}$ Anomalies such as variations in tooth number, abnormal tooth shapes and positions are often found in patients with cleft of the lip and palate. The most frequently affected is permanent lateral incisor. In general, the tooth is congenitally absent; also, anomalies of shape and size like pegshape and enamel hypoplasia are found. ${ }^{[6]}$

For the cleft palate patients, each case should be taken into account with a specific rehabilitation strategy as every deformity has its own orientation. Prosthetic approach is generally a necessary step in the whole treatment plan after the essential orthodontic and surgical procedures are examined. The patient may be treated with a variety of choices including conventional

\begin{tabular}{|l|l|}
\hline \multicolumn{2}{|c|}{ Access this article online } \\
\hline Quick Response Code: & Website: \\
\cline { 1 - 2 } & www.ejgd.org \\
\cline { 1 - 2 } & \\
\hline
\end{tabular}

or implant assisted removable dentures or fixed partial dentures (FPD). Within a comprehensive planning, remaining teeth and roots, deformation of maxillary segments, residual palatal defects, and the disproportion between maxillar and mandibular alveolar ridge should be considered. ${ }^{[2]}$ Such a prosthetic rehabilitation would not only make the function and aesthetics better but also maintain and improve the oral health. ${ }^{[7]}$

\section{CASE REPORT}

A 21-year-old female patient was referred to the Department of Prosthodontics with an unaesthetic appearance and irregular occlusion after a 4 year of surgically assisted orthodontic unilateral cleft palate therapy. She had treated with reverse headgear at first. However, skeletal Class III relation couldn't be corrected as she hadn't used it properly. For that reason, bilateral modus distractors were positioned at zygoma to stimulate the protrusion of maxilla with asymmetric activation. Despite a successful surgery, lack of usage of her post-surgical palatal plate resulted with insufficient occlusion and the predicted position of maxilla couldn't be gained [Figure 1].

In the intra-oral examination; irregular maxillary teeth alignment and occlusion were observed. The unilateral cleft remained on the alveolar bone crest between the right central incisor and the canine with the lateral incisor missing and that caused an asymmetric appearance. The anterior relation was in a tet-a-tet position. In both posterior sides, disclusion was obvious and only the contrary molar teeth were in contact. 
Nevertheless, it wasn't enough to form a sufficient occlusal relation [Figure 2]. Around the cleft region, upper teeth were inadequately overlapping the lower teeth when the jaw was closed although the clinical crown lengths of premolars were ideal. However, the canine which was adjacent to the remaining fistula was not fully erupted and it was a grade 2 mobile tooth according to Miller Index for teeth mobility. Besides, gingival tissue was contracted by scar formation in the labial surface of canine. While the upper jaw was so disorganized, the mandible had only one missing tooth which was the right first molar. Oral hygiene was insufficient due to irregularly positioned and displaced teeth with lack of occlusion.

Working casts were prepared to make a diagnostic wax- up. By this way, the ideal teeth alignment and the tooth reduction needed for abutments were clearly put forward. Then, all maxillary crowns were prepared except second molars. After the gingival retraction of the abutments with cords, the subgingival margins were finished in a champher. The marginal preparation of mobile canine was restricted at gingival level and a shallow champher was prepared without a bevel as McKinstry ${ }^{[8]}$ has been suggested. The occlusal reductions on the right premolars were refrained due to increased interarch distance [Figure 3].

The mobile canine was reinforced with two abutment teeth on the left, three abutment teeth on the right

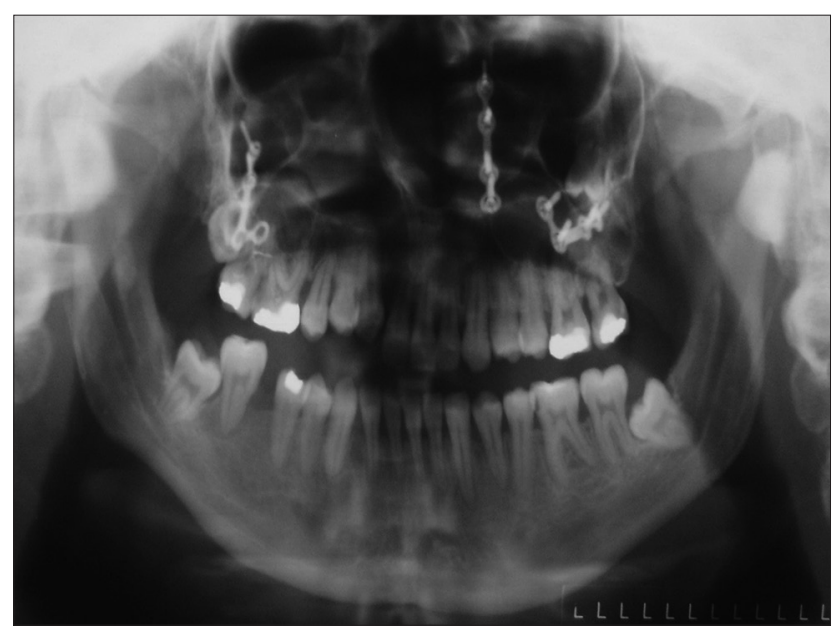

Figure 1: Panoramic radiograph of the patient referred for prosthetic evaluation forming a six unit FPD. Left lateral incisor was sustained with left canine whereas left premolars and first molar were not connected to each other and left as single units. Two ledges were prepared on the lingual surface of right central incisor and first premolar in the metal framework. Second structure which consisted of the missing right lateral incisor and right canine was manufactured after the adjustment of the main framework was accomplished. The connection was obtained by inner surfaces seated bracing arms and an attachment system (VKS-SG Attachment System, Bredent, Germany). Both prepared ledges were supposed to permit the bracing arms to be inlayed with normal contours of the teeth. A ball shaped male key had been positioned horizontally onto the palatal fossa of canine copping whereas the female keyway was inserted in the second framework [Figure 4].

\section{DISCUSSION}

In $\% 93$ of the cleft patients, teeth neighboring to the cleft are responsible for the high degree of mobility which is a result of diminished bone support. The bone levels of teeth proximal to the cleft were found to be located more apically at the side facing the defect than on the opposing side. ${ }^{[9-11]}$ Furthermore, lack of function may allow resorption of bone and this can be inhibited by regaining the functional capacity with a suitable prosthesis. The prosthetic treatment of cleft lip and palate patients can be either done by removable dentures or FPD. The multi-unit fixed restorations also serve to split the mobile teeth with arch stabilization and perceptive splinting is beneficial and enhances the longevity of the restoration with optimal function and aesthetics. ${ }^{[12-14]}$ Unfortunately, an FPD facilitates bacterial accumulation and complicates its elimination.

A multi-unit FPD acts as a massive body to distribute the biting force among the supporting abutments, thereby contributing to restore functional loading capacity. ${ }^{[3]}$ The crown length is important for the distribution of biting forces and influences the amount of the force on the cement layer which causes adhesion problems. In this case, the diagnostic wax-up pattern pointed out the leverage effect of restored crowns due to their excessive length to occlude on the right side. Hence, another FPD on the mandibular molar region was projected in order to prevent an excessive moment load on the cleft region. The second framework and the intrinsic design involved also

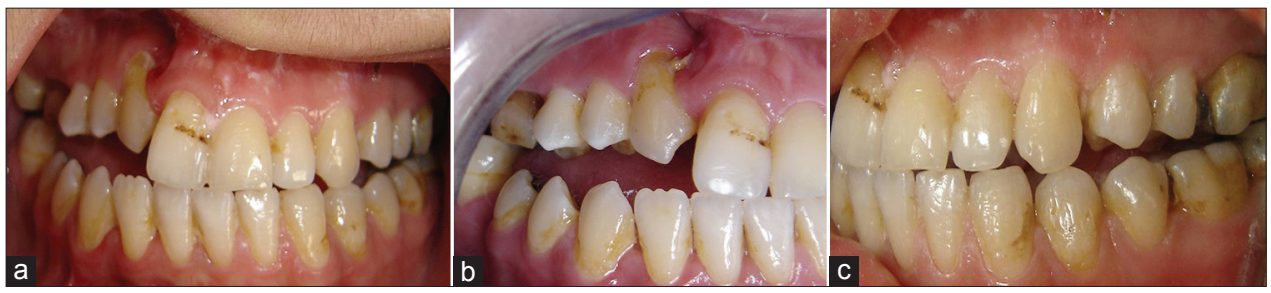

Figure 2: (a) Frontal view of the patient; (b) and (c) Lateral views of the patient showing insufficient occlusion 
ensured maximally favorable biting force transmission, since the latter always takes place axial to the teeth. The palatal ledges, for instance, were prepared for the stability of the second framework and to distribute the occlusal stress vertically to the adjacent abutments.

While keeping on rehabilitation strategy, the number of abutments required reaching the stability and increase the loading capacity of the cleft area was taken into consideration. ${ }^{[14]}$ Some authors have reported various suggestions for the quantity of the abutments to provide adequate stability and prevent buccal segment collapse around the cleft region ${ }^{[14-16]}$ Suzuki et al. ${ }^{[17]}$ have demonstrated that in patients with unilateral cleft palate, FPD should include two teeth in each segment in the abutment of splint across the cleft in order to obtain the equality of the functional loading capabilities of the upper and lower jaw. They have stated that the addition of more teeth has no greater effect than two supported teeth on both sides. Besides, according to the long-term study of Ramstad and Jendal ${ }^{[18]}$, the dental change seemed to be the greatest for the first molars followed by premolars and canines and premolars and first molars became medially displaced behind anterior teeth giving the maxillary anterior teeth a disproportionate prominence. Therefore, permanent retention in the premolar-first molar area is seemingly required to prevent such a change. In this case two adjacent teeth in both sides and right first molar were prepared to establish a six unit FPD.

The prosthetic rehabilitations should also consider the improvement of the current occlusal relation of cleft lip and palate patients. Poor occlusion affects the nutrition of the patient negatively. Thus, the occlusal reconstruction plays a key role for a satisfactory result at the end of the therapy. For this case, the disclusion in both posterior regions restricted the efficiency of mastication. This situation could be easily compensated by a full mouth restoration. Instead, the majority of the sound teeth in mandible were protected and the occlusion was accomplished by restoring only the upper teeth. Finally, the required occlusion was constructed and masticator function was regained.

Bacterial plaque accumulation is enhanced due to the irregularly positioned teeth and inadequate personal oral hygiene care. ${ }^{[17,18]}$ In cleft palate patients, use of a multi-unit FPD may increase the difficulty in oral hygiene management. In this case, the extended embrasures around the canine which was adjacent to the remaining fistula simplified the application of interdental floss and interdental brush and prevented the possible problems [Figure 5]. In addition, as the patient may remove the secondary structure in turn facilitates hygiene of the dental abutments particularly when compared with the cleaning difficulties associated with a conventional FPD. ${ }^{[19]}$ Secondly, the marginal adaptation of mobile canine copping was performed with a polished metal surface.

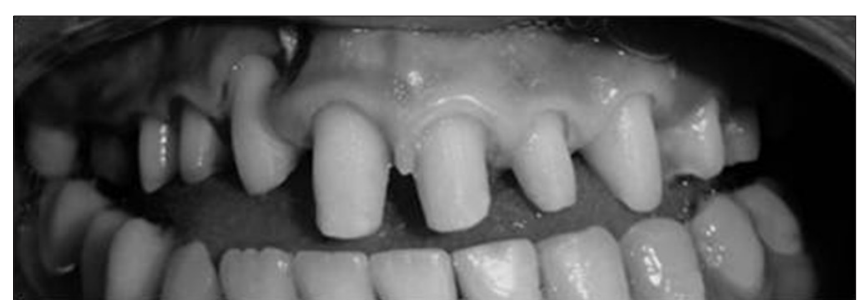

Figure 3: Preparation of maxillary teeth

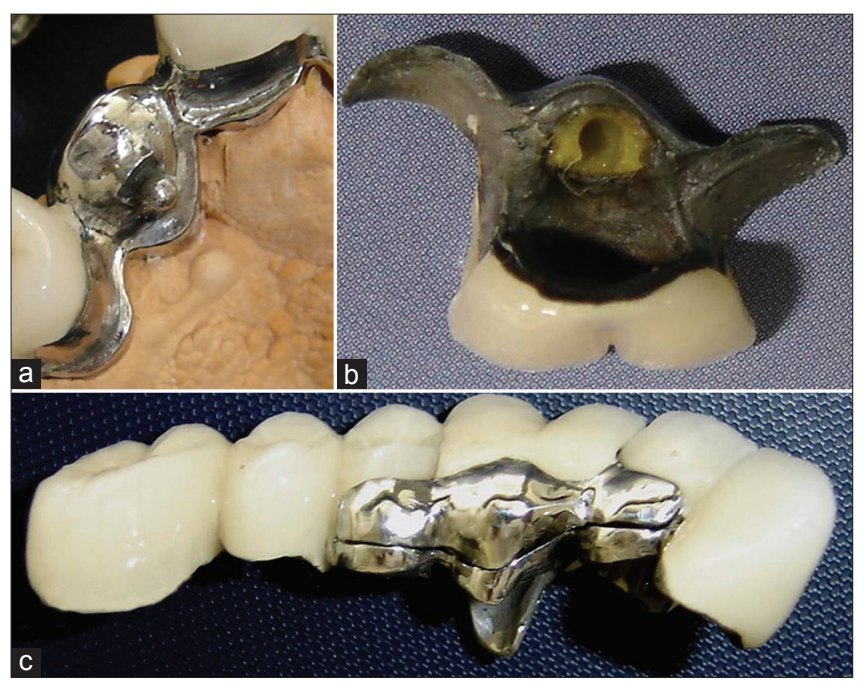

Figure 4: (a) Main framework with ball shaped male key and lingual ledges; (b) The interface of the removable crown complex with female keyway and bracing arms; (c) Final adaptation of the modified FPD

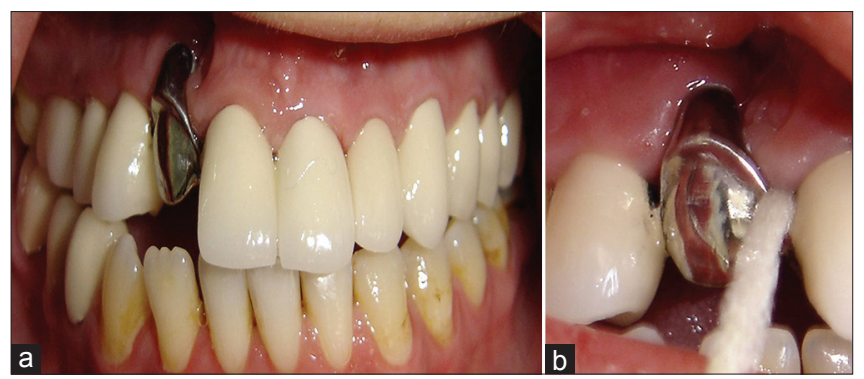

Figure 5: ( $a$ and b) Polished metal surface and extended embrasures facilitate the elimination of bacterial accumulation

Doddamani et al. ${ }^{[20]}$ applied an FPD with pink porcelain to mask the soft tissue defect for aesthetics. In our case, the polished metal surface was not affecting the aesthetics at all and it was thought that bacterial adhesion would be harder compared to a porcelain surface.

The removable crown complex did not only prevent the abutments from the possible leverage effect and help to improve oral hygiene management but also contributed the enhancement of aesthetics. The space between the right first premolar and the right central incisor was too wide for a single abutment whereas it was insufficient to be replenished by a lateral incisor as a pontic and the canine abutment adjacent to it in the proposal multi unit FPD. In order to compensate this problem, a 


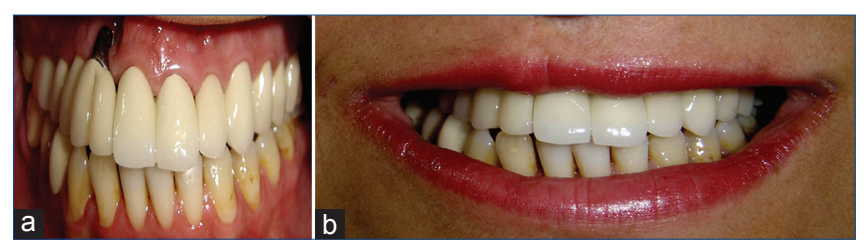

Figure 6: $(a$ and $b)$ Final restoration including the removable crown complex creates a symmetrical alignment with an illusionary effect. The lip position also contributes aesthetics by masking the polished metal surface

second framework was adjusted onto canine abutment of FPD with a precision attachment system and prepared ledges. This helped to increase intra-arch distance and prohibited the restoration to be over-contoured. The second framework also brought a solution for aesthetics in an illusionary manner. The distal slope of the canine was narrowed to create an adequate space for its mesial slope and a lateral incisor. The conspicuous convexity of middle labial lobe of the canine was dominant enough to mask the disproportion between the slopes by which a symmetric and aesthetic tooth alignment in the anterior region of upper jaw was accomplished [Figure 6].

A retention problem between two prostheses would be expected in the future due to deformation of the keyway. Although this problem can be easily compensated by replacement of the keyway and renewing of both prostheses is not required.

\section{CONCLUSION}

For cleft lip and palate patients, the maintenance and improvement of oral hygiene, function and aesthetics are not negligible aspects. Such a design of an FPD including a removable crown complex will act as a permanent retainer for the abutments, help to preserve the oral health, ease mastication and enhance the aesthetics in an illusionary manner. Contingency plans should be available to develop and modify the prosthesis to achieve ideal oral health.

\section{REFERENCES}

1. McGivney G, Castleberry JD. McCraken's Removable Partial Prosthodontics. $8^{\text {th }}$ ed. Toronto; Mosby Company; 1989.

2. Vojvodic D, Jerolimov P. The cleft palate patient: A challenge for prosthetic rehabilitation - Clinical report. Quintessence Int 2001;32:521-4.

3. Mañes Ferrer JF, Martínez González A, Oteiza Galdón B, Bouazza Juanes K, Benet Iranzo F, Candel Tomás A. Telescopic crowns in adult case with lip and palate cleft. Update on the etiology and management. Med Oral Patol Oral Cir Bucal 2006;11:E358-62.

4. Strickland F, Psillakis JJ, Grbic JT, Wright RF. Prosthodontic rehabilitation of the adult cleft patient: A case report. Columbia Dental Review 2004;9:1-9.

5. Camilleri S, Diacono M. Bone graft stabilisation with an osseointegrated implant retained prosthesis. Malta Medical J 2005;17:39-43.

6. Oosterkamp BC, Dijkstra PU, Remmelink HJ, van Oort RP, Sandham A. Orthodontic space closure versus prosthetic replacement of missing upper lateral incisors in patients with bilateral cleft lip and palate. Cleft Palate Craniofac J 2010;47:591-6.

7. Murat S, Gurbuz A, Genc F. Prosthetic rehabilitation of a patient with bilateral cleft lip and palate using osseointegrated implants and extracoronal resilient attachments: A case report. Cleft Palate Craniofac J 2011;48:342-7.

8. McKinstry RE. Cleft Palate Dentistry Pittsburgh: ABI Professional Publications; 1998. p. 36-263.

9. Gaggl A, Schultes G, Karcher H, Mossböck R. Periodontal disease in patients with cleft palate and patients with unilateral and bilateral clefts of lip, palate and alveolus. J Periodontol 1999;70:171-8.

10. Mombelli A, Bragger U, Lang NP. Microbiota associated with residual clefts and neighboring teeth in patients with cleft lip, alveolus and palate. Cleft Palate Craniofacial J 1992;29:463-469.

11. Reisberg DJ. Dental and prosthodontic care for patients with cleft or craniofacial conditions. Cleft palate Craniofacial J 2000;37:534-7.

12. Watanabe I, Kurtz KS, Watanabe E, Yamada M, Yoshida N, Miller AW. Multi-unit fixed partial denture for a bilateral cleft palate patient: A clinical report. J Oral Rehabil 2005;32:620-2.

13. Moore D, McCord F. Prosthetic dentistry and the unilateral cleft lip and palate patient, the last 30 years, a review of the prosthodontic literature in respect of treatment options. Eur J Prosthodont Rest Dent 2004;12:70-4.

14. Kernahan DA, Rosenstein SW, editors. Cleft Lip and Palate: A System of Management. Baltimore, Md: Williams and Wilkins; 1990. p. 313

15. Iida T, Mukohyama $\mathrm{H}$, Inoue $\mathrm{T}$, Oki M, Suzuki R, Ohyama T, et al. Modal analysis of maxillary dentition in cleft lip and palate patients before and after bone grafting. J Med Dent Sci 2001;48:87-94.

16. Ohyama T. Prosthodontic considerations for patients with cleft lip and palate. Int Dent J 1986;36:140-5.

17. Suzuki R, Taniguchi H, Ohyama T. Prosthodontic Abutment in Four Patients with Unilateral Cleft Lip and Palate. Cleft Palate Craniofacial J 1995;32:442-7.

18. Ramstad T, Jendal T. A long-term study of transverse stability of maxillary teeth in patients with unilateral complete cleft lip and plate. J Oral Rehabil 1997;24:658-65.

19. Wolford LM, Stevao ELL. Correction of jaw deformities in patients with cleft lip and palate. Bumc Proceedings 2002;15:250-4.

20. Doddamani S, Patil RA, Nerli S. Multidisciplinary approach for improving esthetics in cleft palate and alveolus patient: A clinical report. J Indian Prosthodont Soc 2005;5:39-42.

How to cite this article: Bavbek AB, Culhaoglu AK. An illusionary prosthetic design for a unilateral cleft palate patient. Eur J Gen Dent 2014;3:71-4. Source of Support: Nil, Conflict of Interest: None declared. 